\title{
Impacts of vegetation and groundwater dynamics on warm season precipitation over the Central United States
}

\author{
Xiaoyan Jiang, ${ }^{1}$ Guo-Yue Niu, ${ }^{1}$ and Zong-Liang Yang ${ }^{1}$ \\ Received 9 July 2008; revised 19 November 2008; accepted 21 January 2009; published 21 March 2009.
}

[1] We investigated the impacts of vegetation and groundwater dynamics on warm season precipitation by using the Weather Research and Forecasting (WRF) model coupled with a modified Noah land surface model (LSM). The modified Noah LSM was augmented with an interactive canopy model and a simple groundwater model (SIMGM). A series of experiments performed shows that incorporating vegetation and groundwater dynamics into the WRF model can improve the simulation of summer precipitation in the Central United States. The enhanced model produces more precipitation in response to an increase in the latent heat flux. The advantage of incorporating the two components into the model becomes more discernable after 1 month. The model results suggest that the landatmosphere feedback is an important mechanism for summer precipitation over the Central United States. Vegetation growth and groundwater dynamics play a significant role in enhancing the persistence of intraseasonal precipitation in regional climate models. Their combined effects act to favor a stronger land-atmosphere feedback during the summer season. The simulated diurnal cycle of precipitation is improved by the WRF model with the augmented Noah LSM. Moreover, we found that the coupling between the soil moisture and the lifting condensation level (LCL) is enhanced by adding the two components to the WRF model. The impact of groundwater is significant when the soil moisture is relatively dry. This study suggests that incorporating vegetation and groundwater dynamics into a regional climate model would be especially beneficial for seasonal precipitation forecast in the transition zones.

Citation: Jiang, X., G.-Y. Niu, and Z.-L. Yang (2009), Impacts of vegetation and groundwater dynamics on warm season precipitation over the Central United States, J. Geophys. Res., 114, D06109, doi:10.1029/2008JD010756.

\section{Introduction}

[2] The predictability of precipitation on timescales of days to years is largely limited by the effects of atmospheric noise, which restricts weather forecasts beyond about two weeks [e.g., Lorenz, 1963, 1969]. The hope to improve intraseasonal to seasonal precipitation forecasts largely relies on simulating the atmospheric response to slowly varying states of the land surface [Beljaars et al., 1996; Koster et al., 2004] and the ocean [e.g., Wallace et al., 1998], which can be predicted weeks to months in advance. In midlatitude and in the interior of those large continents such as the North America, oceanic impact on precipitation is small relative to that of land soil moisture as suggested by recent studies using atmospheric general circulation models (GCMs) [e.g., Koster and Suarez, 2000; Koster et al., 2004; Dirmeyer, 2006]. Understanding complex interactions between the land surface and atmosphere is central to better predicting precipitation over land.

\footnotetext{
${ }^{1}$ Department of Geological Sciences, John A. and Katherine G. Jackson School of Geosciences, University of Texas, Austin, Texas, USA.

Copyright 2009 by the American Geophysical Union. 0148-0227/09/2008JD010756\$09.00
}

[3] Studies of such coupled system problems are often conducted by using coupled land-atmosphere models. A number of studies with the use of coupled GCMs have shown that soil moisture is particularly important for maintaining long-term climate and its temporal variability [e.g., Koster et al., 2004; Dirmeyer, 2006; Guo et al., 2006]. Koster et al. [2004] concluded that a strong coupling exists in the transition zones between dry and wet regions such as the Central United States (U.S.). Dirmeyer [2006] quantified the strength of the hydrologic cycle between the land and atmosphere, and found that in the dry regions, specified precipitation anomalies can contribute to the latent heat flux anomalies immediately; while in the wet regions, precipitation is not very sensitive to soil moisture anomalies. In the transition zones, the soil moisture-precipitation coupling can be best preserved, which is consistent with the work of Koster et al. [2004]. Guo et al. [2006] revealed that differences in the coupling strengths exist among different models, and that these differences are related to different values of evapotranspiration (ET) simulated over land. These studies suggest that there remain uncertainties in representing soil moisture processes and their coupling with other physical processes in land surface models (LSMs).

[4] Most LSMs used in the above mentioned studies did not include an interactive vegetation canopy and a dynamic water table. Neglecting short-term response of vegetation 
greenness and leaf amounts to precipitation and temperature may yield an underestimate or overestimate of latent heat flux. Several studies have shown that changes in vegetation phenology can have a strong influence on regional climate through partitioning sensible and latent heat fluxes [Chase et al., 1996, 2000; Hoffmann and Jackson, 2000; Matsui et al., 2005; Liu et al., 2006; Wang et al., 2006a, 2006b; Xue et al., 2006; Dekker et al., 2007; Dong et al., 2007; Notaro et al., 2007]. Matsui et al. [2005] applied satellite-derived vegetation greenness fraction (VGF) in a regional climate model to account for the temporal and spatial variations of vegetation distribution. Their results showed that there was a strong link among the evaporative fraction, surface temperature, and relative humidity in the boundary layer. However, their results did not reveal that a higher VGF could lead to more precipitation. By adding a sophisticated photosynthesis scheme in a coupled mesoscale model, Holt et al. [2006] found that the atmospheric model is able to better respond to the detailed representation of soil moisture and temperature, and the model performance is improved. Kim and Wang [2007] examined the positive soil moisture-precipitation feedback over North America on a seasonal timescale. Their results showed that soil moisture-induced precipitation increase is enhanced under wet summer soil moisture anomalies when vegetation phenology is included in their model. To further investigate the impact of the vegetation growth on precipitation, a better representation of vegetation growth response to climate conditions in coupled land-atmosphere models is needed.

[5] Like vegetation, which in turn, can feed back to precipitation, groundwater also can respond to precipitation rapidly. However, most LSMs traditionally ignored groundwater dynamics. In recent years, different approaches to incorporating groundwater dynamics into land surface processes have been developed [e.g., Gutowski et al., 2002; Liang et al., 2003; Yeh and Eltahir, 2005; Maxwell and Miller, 2005; Niu et al., 2007; Fan et al., 2007; Maxwell et al., 2007; Kollet and Maxwell, 2008; Anyah et al., 2008]. These studies incorporated groundwater processes into LSMs and demonstrated the significant impacts of considering surface and groundwater dynamic interactions on surface fluxes and soil moisture in land surface modeling. Some of the approaches used in these studies [e.g., Yeh and Eltahir, 2005; Niu et al., 2007] use the water table as the lower boundary, while others do not [Liang et al., 2003]. Moreover, some studies even included detailed lateral flow. Famiglietti and Wood [1994] parameterized groundwater dynamics in a LSM using a TOPMODEL concept [Beven and Kirkby, 1979] and found the lateral redistribution of surface and subsurface soil water in a small-scale model is critical in controlling both runoff production and energy balance. Seuffert et al. [2002] examined how the incorporation of a land surface hydrologic model in a mesoscale weather prediction model affects surface energy fluxes, structure of the atmospheric boundary layer, and precipitation. They found that a better representation of soil hydrologic processes improves the predicted energy fluxes and rainfall. York et al. [2002] developed a coupled aquifer-land surface-atmosphere model, and found that the physically based model was able to reproduce monthly and yearly trends in precipitation, stream discharge, and ET, for a catchment. More recently, Maxwell et al. [2007] and Maxwell and Kollet [2008] coupled a groundwater flow model with an atmospheric model to examine the effects of soil moisture heterogeneity on atmospheric boundary layer processes. Their studies showed that the fully coupled model was able to capture a realistic soil moisture distribution. The study of Maxwell and Kollet [2008] also revealed that groundwater is a key to understanding processes of recharge and drought under a changing climate, especially in the critical zones where the water table depth is neither very shallow nor very deep. They found a strong correlation between the water table depth and land surface energy. These studies all suggest the need for a better understanding of the role of subsurface processes in the overlying atmosphere. However, most of these studies have been focused on relatively small (e.g., catchment or watershed) scales. The exception of work includes Anyah et al. [2008] and Yuan et al. [2008], who studied the influences of groundwater on land-atmosphere coupling on a continental scale. Despite a large body of research as cited above, it remains unanswered that how the inclusion of groundwater dynamics affects precipitation in the transition zones, as these regions are very sensitive to soil moisture.

[6] The goal of this paper is to examine the impacts of vegetation and groundwater dynamics on warm season precipitation on a continental scale. We focus on the Central U.S., which has been identified by Koster et al. [2004] as a hot spot. The study is aimed at understanding the influences of vegetation and groundwater dynamics on intraseasonal precipitation in the warm season. The impacts of the two components are investigated through application of a shortterm vegetation phenology model and a groundwater model. In this work, we hypothesize that including vegetation growth and groundwater dynamics in a coupled land-atmosphere model can improve intraseasonal to seasonal predictions of precipitation and have a strong effect on the coupling between the land and atmosphere over the Central U.S. We begin in section 2 with a brief description of the coupled land-atmosphere model and experiments. The role of initialization in seasonal forecasting is taken into account through ensemble simulations. In section 3, we evaluate the model results against available observations and examine the roles of vegetation growth and groundwater dynamics in precipitation and surface fluxes. Furthermore, the impacts of these processes on diurnal cycles of climate variables are investigated. Finally, the effects of the new components on the relationship between soil moisture and lifting condensation level (LCL) are examined.

\section{Model Description and Experimental Design 2.1. Model Description}

[7] A nonhydrostatic, fully compressible model, the Weather Research and Forecasting (WRF) model, is used as an investigative tool in this study [Skamarock et al., 2005]. The model (1) includes interactive nested grid capabilities; (2) supports various cumulus schemes, microphysics, shortwave and longwave radiation schemes; and (3) includes two options of LSMs. We used WRF model 2.1.2, which contains all of the above features plus timevarying sea surface temperature (SST) and prescribed monthly changing VGF. These time-varying lower bound- 


\section{WRF model}

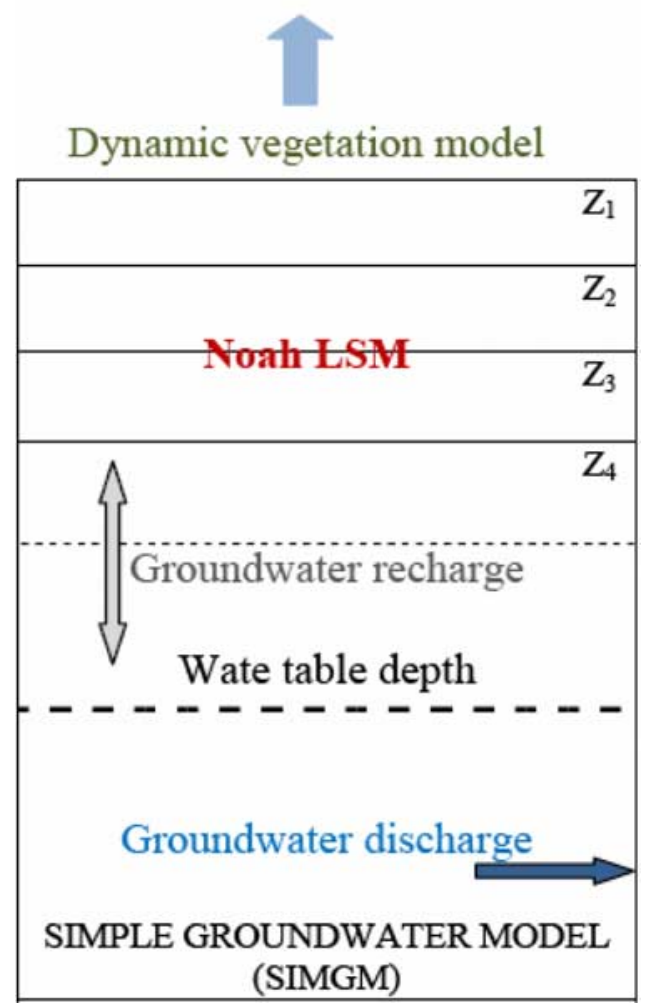

Figure 1. Schematic diagram of a coupled land-atmosphere modeling system. A dynamic vegetation model (DV) is incorporated into the Noah LSM, and a simple groundwater model (SIMGM) is added beneath the Noah LSM.

ary conditions are important for monthly to seasonal climate simulations.

[8] To assess the impacts of vegetation phenology on warm season precipitation over the Central U.S., an interactive canopy model [Dickinson et al., 1998; Yang and Niu, 2003] has been coupled to the WRF model (Figure 1). The interactive canopy model (or called dynamic vegetation model) has two major parts: a stomatal conductance-photosynthesis part and a dynamic leaf part. The first part computes carbon assimilation through photosynthesis of both sunlit and shaded leaves following Collatz et al. [1991]. The second part describes carbon allocation to different vegetation components (leaf, stem, root etc.), respiration, and vegetation phenology. A more detailed description of this canopy model can be found in Dickinson et al. [1998]. We added this canopy model to the Noah LSM [Chen and Dudhia, 2001] by converting the predicted leaf area index (LAI) to VGF using the following exponential function:

$$
V G F=1-\exp \left(-\frac{2.5}{6.5} L A I\right)
$$

Following the methods used in Dickinson et al. [1998], we parameterized water stress on conductance as a function of soil water matric potential rather than a function of soil moisture in the Noah LSM.
[9] We also included a simple groundwater model (SIMGM) developed by Niu et al. [2007] in the Noah LSM to investigate the influences of groundwater dynamics on precipitation. As aforementioned, several previous studies have incorporated groundwater models into LSMs, and some of them even included lateral flow [e.g., Seuffert et al., 2002; Maxwell et al., 2007]. In this work, we did not explicitly include the effects of lateral flow, because our model grid spacing is coarse $(\sim 32 \mathrm{~km})$. At such a coarse grid, the vertical water exchange between soil and its underlying unconfined aquifer is considered to be more important than the horizontal water exchange. The soil in the Noah LSM has four layers with a total depth of $2 \mathrm{~m}$. In the present study, SIMGM is added beneath the fourth soil layer of Noah LSM, allowing the interaction between soil moisture and groundwater (Figure 1). SIMGM represents the vertical exchange of water between the bottom soil layer and the unconfined aquifer by parameterizing the recharging rate to the aquifer that has been added as a single integration element below the bottom soil layer. Therefore it takes into account not only gravitational drainage from the soil to the aquifer when soil is relatively wet (the total water head at the bottom soil layer is greater than that at the water table), but also upward diffusion of water from the aquifer driven by capillary forces when the soil is dry (the water head at the water table is greater than that at the bottom soil layer). The water table depth was solved by converting the water storage in the aquifer through specific yield [Niu et al., 2007]. In SIMGM, a simple TOPMODEL-based subsurface runoff scheme, expressed as an exponential function of the water table depth, was used to parameterize groundwater discharge. To be consistent with the subsurface runoff scheme, the surface runoff scheme was also replaced with a simple TOPMODEL-based surface runoff scheme, which used an exponential function of the water table depth to represent the fractional saturated fraction [Niu et al., 2005]. The lateral transport of groundwater between grid cells and to rivers is considered implicitly through the TOPMODEL base flow formulation.

\subsection{Experimental Design}

[10] To understand the effects of vegetation and groundwater dynamics on precipitation and their impacts on land and atmosphere interactions, a series of ensemble numerical experiments with each lasting three months were performed. In all simulations, we used the Lin et al.'s microphysics scheme [Lin et al., 1983], the Kain-Fritsch Cumulus Parameterization scheme [Kain and Fritsch, 1990], the Yonsei University Planetary Boundary Layer (PBL) scheme [Hong and Pan, 1996], the Simple Cloud Interactive Radiation scheme [Dudhia, 1989], the Rapid Radiative Transfer Model Longwave Radiation scheme [Mlawer et al., 1997] and the Noah LSM. The modeling domain covers the entire contiguous U.S. on a 32-km horizontal grid (Figure 2). The initial and lateral boundary conditions were derived from the NCEP's North American Regional Reanalysis (NARR) data set, which has a domain covering our configured computational area [Mesinger et al., 2006]. The NARR data were generated at a 3-hour interval with the use of the NCEP Eta model, its data assimilation system and a recent version of the Noah LSM at $32 \mathrm{~km} / 45$ layer resolution. The system used to generate the NARR data also includes 


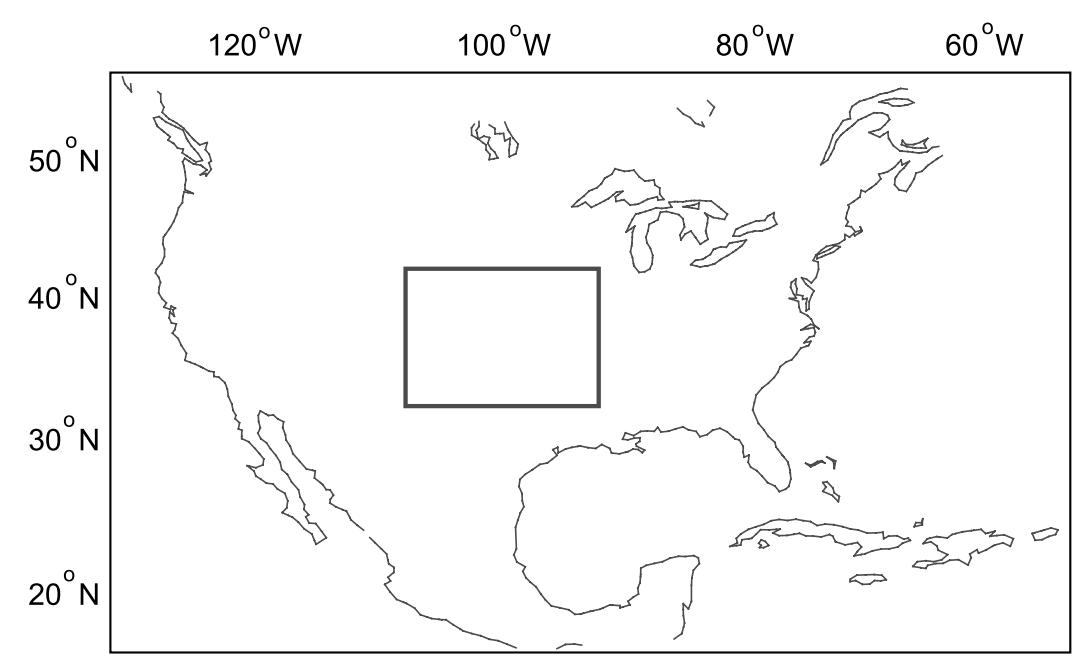

Figure 2. Map showing the modeling domain in which the shaded area represents the Central United States.

hourly assimilation of precipitation. Since the focus of this study is on summer season, we selected June, July and August (JJA), 2002 as our simulation period. This period is also associated with less-than-normal precipitation in June over the western U.S. and adjacent High Plains, and morethan-normal precipitation in July and August over part of Texas and the northern Great Plains. As June is relatively dry, soil moisture may dry out in the default modeling system, resulting in poor model performance in the ensuing months because of the lack of the detailed subsurface processes (e.g., groundwater system). In this case, we expect that new improvements in the LSM could lead to better simulations of precipitation, in particular in the months of July and August.

[11] To test the impacts of new components, three different experiments were performed (Table 1). The first one, called DEFAULT, is a control run without any changes to the Noah LSM. The Noah LSM in this modeling system uses prescribed climatological VGF data derived from the Normalized Difference Vegetation Index (NDVI) collected by the NOAA-Advanced Very High Resolution Radiometer (AVHRR) sensor. Although recent NDVI data acquired from the Moderate Resolution Imaging Spectroradiometer (MODIS) sensor appear to be more accurate than the AVHRR-derived NDVI data, Gallo et al. [2004] found 16-day composite values of the two data sets over the same time periods and a variety of land cover classes within the contiguous U.S. are quite similar over the 23 intervals of 2001 that were analyzed. Since the purpose of incorporating dynamic vegetation into the model is to make the model capable of predicting vegetation growth and its interaction with atmosphere, we used AVHRR derived climatological VGF as experimental data in DEFAULT. Thus DEFAULT does not allow vegetation to grow in response to climate change. By incorporating the dynamic vegetation model into the default Noah LSM, the second experiment (DV) allows vegetation growth to respond to climate change. DV investigates whether considering the vegetation-precipitation feedback in the coupled model improves the forecast. The third experiment (DVGW) implemented SIMGM to DV to simultaneously represent vegetation growth and water table dynamics. For each experiment, five-member ensemble simulations for three months (JJA) were constructed starting from different initial dates: 00Z 31 May 2002, 06Z 31 May 2002, $12 Z 31$ May 2002, 1831 May 2002 and $00 Z 1$ June 2002. The five members for each experiment only differ in their starting times. While the three modeling systems utilize the same combinations of physical parameterization schemes such as cumulus parameterization scheme, they differ in the use of dynamic vegetation and groundwater models in the Noah LSM. We updated SSTs every six hours during the model integration.

[12] The initial values of land surface variables, especially soil moisture exert a strong control on seasonal forecast in regional climate models [Pielke et al., 1999]. In order to minimize the effects of initial conditions, we used the same sets of land surface variables in all three experiments, with the same starting dates having the same initial conditions. All initial values of land surface variables, except for the water table depth and VGF, are from the NARR data set. It should be pointed out that the modeling system employed to produce NARR data also utilizes the Noah LSM. The initial values of VGF required to initialize DV and DVGW are the same as those used in DEFAULT. We also prepared initial values of water table depth needed by the groundwater component in the coupled model by running the offline Noah LSM coupled with SIMGM. To do so, offline runs were conducted from January 2000 to December 2002 and the spin-up enabled the model to reach an equilibrium state [Yang et al., 1995]. Then, the values of water table level on 1 June 2002 were used to initialize the water table depth and water storage for SIMGM in the coupled model.

[13] These designed experiments allow us to better identify the key mechanisms and processes involved in the landatmosphere feedback. Consequently, the differences between

Table 1. Design of Experiments

\begin{tabular}{ll}
\hline Experiment & \multicolumn{1}{c}{ Description } \\
\hline DEFAULT & prescribed VGF \\
DV & predicted VGF (or dynamic vegetation) \\
DVGW & predicted VGF and water table depth \\
\hline
\end{tabular}



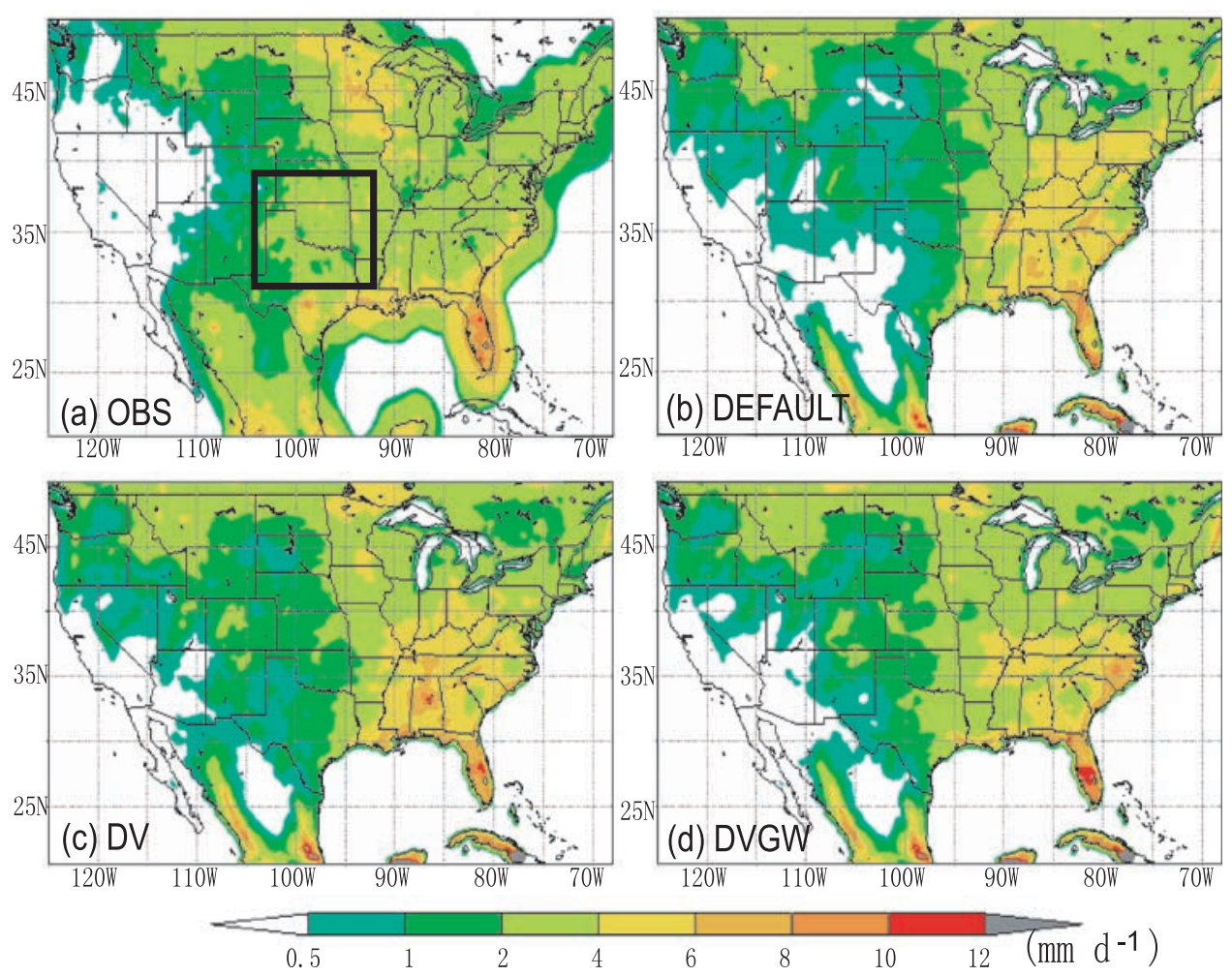

Figure 3. Observed and simulated precipitation in June, July, and August (JJA) 2002 over the contiguous United States. (a) Observed JJA precipitation from the Climate Precipitation Center (CPC) unified precipitation data set, which is a gridded data set at $0.25^{\circ} \times 0.25^{\circ}$ resolution covering the United States and Mexico. (b) Simulated JJA precipitation in DEFAULT, which uses prescribed monthly mean vegetation greenness fraction (VGF). (c) Simulated JJA precipitation in DV, which includes a dynamic vegetation model, allowing the vegetation growth in response to climate conditions. (d) Simulated JJA precipitation in DVGW, which is augmented with SIMGM and DV to represent vegetation growth and water table dynamics.

DEFAULT and DV were used to evaluate the impacts of vegetation dynamics on surface heat fluxes and precipitation. Similarly, differences between DV and DVGW were used to reveal the contribution of groundwater variations to vegetation phenology, surface heat fluxes and precipitation.

\section{Results}

\subsection{Impact on Precipitation}

[14] To reiterate, the objective of this work is to assess how seasonal and intraseasonal evolution and patterns of precipitation are influenced by the improvements in the LSM. Although the ensemble spread is small at the beginning, it becomes large afterward. To reduce the uncertainties associated with initial conditions, the results presented below are based on the five-member ensemble means of different experiments. The results of the days before 1 June have been discarded to reduce possible spin-up effects. The model-simulated precipitation is evaluated against observed precipitation data set (a gridded data set at $0.25^{\circ} \times 0.25^{\circ}$ resolution covering U.S. and Mexico) downloaded from the Climate Precipitation Center (CPC [Higgins et al., 2000]).

[15] Figure 3 plots the spatial patterns of observed and simulated seasonal precipitation (JJA) over the modeling domain. In general, all three modeling systems reproduce the spatial distribution of precipitation. The observed pre- cipitation pattern for JJA (Figure 3a) is characterized by less precipitation in the western U.S. and more precipitation in the eastern U.S. The Central U.S., where the JJA mean precipitation is about $1-4 \mathrm{~mm} \mathrm{~d}^{-1}$, exhibits a feature of transition zones from the dry western U.S. to the wet eastern U.S. Overall, DEFAULT captures the main patterns and (for the most part) magnitudes of continental precipitation (Figure 3b). It overestimates precipitation in much of the eastern states (e.g., Ohio, Pennsylvania, Kentucky, Tennessee and South Carolina), and underestimates precipitation in the Central U.S.. Comparing precipitation simulated by DV against DEFAULT and observations, we found that DV produces somewhat increased precipitation over the Central U.S. and northern parts of North American Monsoon regions such as New Mexico and West Texas, where rainfall increases by nearly $1 \mathrm{~mm} \mathrm{~d}^{-1}$ (Figure 3c). The majority of the increase in precipitation occurs over the Central U.S. However, it should be noted that the increase in precipitation in parts of the eastern U.S. is not expected, and needs further investigation. Furthermore, as expected the impact of inclusion of groundwater component in DV on JJA average precipitation is extensive, covering most parts of the continent (Figure 3d). Incorporating groundwater dynamics into the model accounts for $1-2 \mathrm{~mm} \mathrm{~d}^{-1}$ increase in JJA average precipitation over the Central U.S. The 


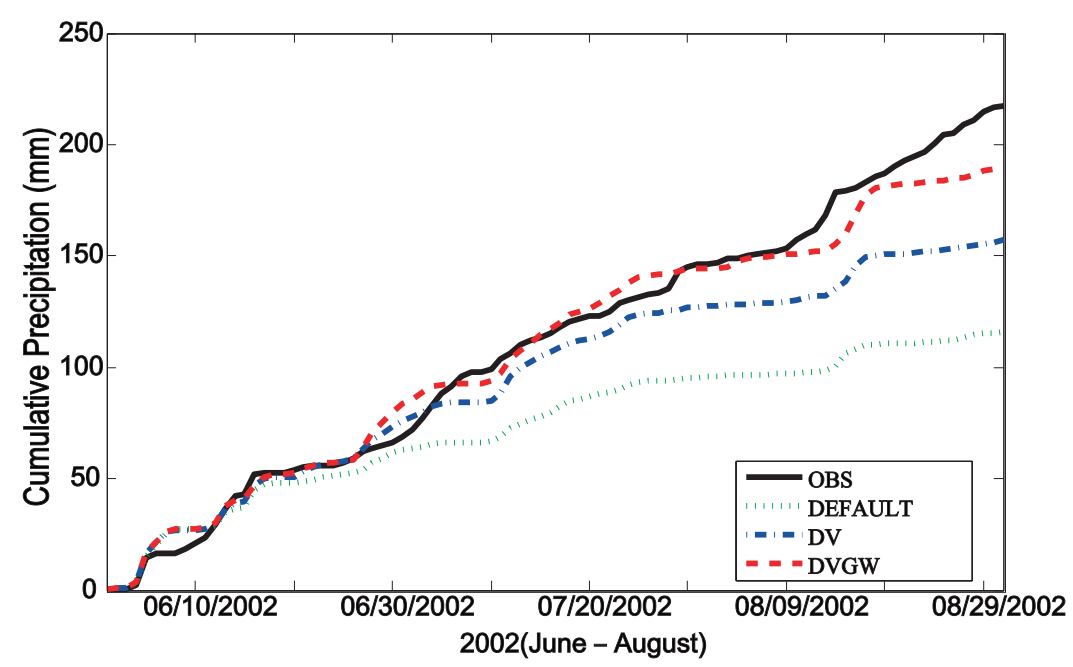

Figure 4. Observed versus simulated cumulative precipitation over the Central United States (DEFAULT, DV, and DVGM are as in Figure 3).

overestimated precipitation in the eastern U.S. is slightly reduced, which we ascribe to the improved TOPMODELbased runoff scheme. Thus one can conclude that adding the two new components to the model tends to result in a substantial increase in precipitation over the Central U.S., improving the model performance. DEFAULT strongly underestimates precipitation in this area by approximately $1 \mathrm{~mm} \mathrm{~d}^{-1}$, while DV and DVGW yield more reasonable estimates. The overestimated precipitation over the eastern U.S. is reduced by the modeling system with the inclusion of new runoff schemes. Future work with the consideration of the effects of lateral flow may further improve model performance.

[16] A comparison of the modeled and measured cumulative precipitation over the Central U.S. is shown in Figure 4. In general, the temporal development of precipitation is fairly reproduced in all three experiments. We also noticed that the three modeling systems have similar performances in June. However, the precipitation amounts simulated by the three modeling systems differ significantly from each other in July and August, and all three modeling systems underestimate precipitation when compared with measurements. The performance of DEFAULT decreased dramatically as the integration time becomes longer. DEFAULT underestimates the JJA precipitation over the Central U.S. by a factor of two. Lo et al. [2008] investigated different dynamical downscaling methods and found that the model with continuous integration tends to have a relatively low skill in simulating long-term climate. In our simulations, DEFAULT shows a decreasing performance in simulating seasonal precipitation. As we incorporated the vegetation effect into the model, the model performance in simulating JJA precipitation is improved. Furthermore, DVGW with the consideration of groundwater effect exhibits the best performance and the difference in cumulative precipitation between DVGW and the observations is the smallest, suggesting that SIMGM is capable of maintaining a reasonable amount of soil moisture and ET in dry seasons by extracting water from deep aquifers. When the soil is drying because of ET, the soil can draw water through capillary suction from the underlying groundwater system, which has a longer memory of the past precipitation events than the soil. This further suggests that the new processes in the coupled model help to maintain reasonable soil moisture. The influences of subsurface processes on precipitation have been examined by other studies [e.g., Seuffert et al., 2002; Bierkens and van den Hurk, 2007; Anyah et al., 2008]. In the study of Seuffert et al. [2002], the authors found that their model with the inclusion of lateral water transport from one soil column to its neighbors reduces simulated precipitation. Without the effects of lateral runoff, their model tends to overestimate precipitation. The current work differs from their study in several aspects including the runoff scheme, the simulation time and the horizontal spatial resolution. Besides, depending on the status of available soil moisture, the impacts of groundwater could be different in different regions. In the current study, we did not consider the lateral water transport. In future studies, this needs to be considered as we investigate the evolution of precipitation. As discussed here, the effect of groundwater is more significant over the transition zone (Central U.S.). Over the eastern U.S., the groundwater tends to reduce overestimated precipitation to some extent, improving the model performance over that region.

[17] Figure 5 shows that the three modeling systems have distinct behaviors in terms of simulating intraseasonal variations of precipitation over the Central U.S. The observed precipitation maintains approximately $2.4 \mathrm{~mm}$ $\mathrm{d}^{-1}$, varying slightly from $2.2 \mathrm{~mm} \mathrm{~d}^{-1}$ in June, $2.6 \mathrm{~mm}$ $\mathrm{d}^{-1}$ in July, to $2.4 \mathrm{~mm} \mathrm{~d}^{-1}$ in August. Although June precipitation is reproduced in the three experiments, there is a pronounced decreasing trend toward the end of the summer season. Compared to observations in JJA, all three modeling systems produce less precipitation, exhibiting an excessive summer drydown. This drydown may, in part, be due to the lack of the lateral water transport in the subsurface. As demonstrated in Bierkens and van den Hurk [2007], the groundwater convergence is a possible mechanism for persistence in rainfall. Therefore we expect that when the lateral water transport is included, the model performance may be further enhanced. Additional work is needed to investigate the mechanisms of these feedbacks, 


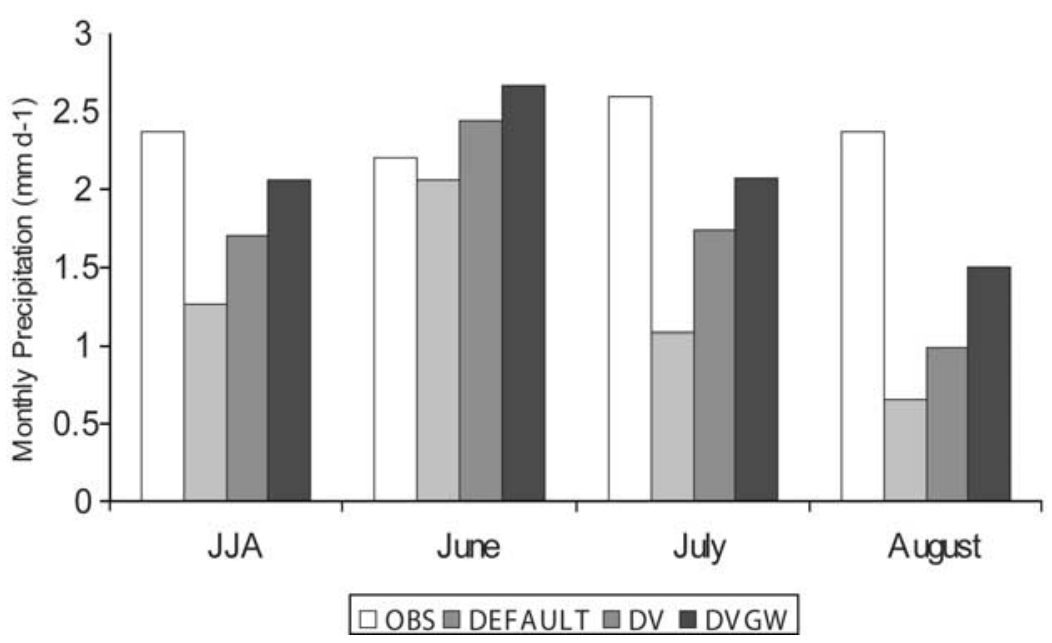

Figure 5. Observed and simulated JJA and monthly mean precipitation $\left(\mathrm{mm} \mathrm{d}^{-1}\right)$ over the Central United States.

which is beyond the scope of this study. Further analysis shows that the largest drying pattern (from $2.4 \mathrm{~mm} \mathrm{~d}^{-1}$ in June to $0.6 \mathrm{~mm} \mathrm{~d}^{-1}$ in August) occurs in DEFAULT. As we introduced vegetation phenology to the default model, the drying trend seen in DEFAULT is significantly ameliorated, with July rainfall at $1.7 \mathrm{~mm} \mathrm{~d}^{-1}$ and August rainfall at $0.98 \mathrm{~mm} \mathrm{~d}^{-1}$. Combined with the implementation of groundwater model, the results are further improved, with July rainfall at $2.1 \mathrm{~mm} \mathrm{~d}^{-1}$ and August rainfall at $1.5 \mathrm{~mm}$ $\mathrm{d}^{-1}$. Clearly, including vegetation and groundwater dynamics in the coupled land-atmosphere model improves the intraseasonal (JJA) precipitation simulations (from $1.3 \mathrm{~mm}$ $\mathrm{d}^{-1}$ in DEFAULT, $1.7 \mathrm{~mm} \mathrm{~d}^{-1}$ in DV, to $2.1 \mathrm{~mm} \mathrm{~d}^{-1}$ in DVGW). The model dry bias in simulating intraseasonal precipitation is reduced most in DVGW. It is worth mentioning that if we just focus on precipitation prediction at one month lead, the advantages of adding the vegetation growth and groundwater dynamics are not so evident. However, if we extend the lead time to two or three months, the advantages of using DV or DVGW become increasingly apparent. This suggests that incorporating vegetation and groundwater dynamics into the model can prolong the soil moisture memory and hence maintain ET in dry seasons, which will be discussed later.

[18] In summary, our model with the two augments performs well in reproducing summer precipitation over the Central U.S. in 2002. The results of precipitation illustrate that the vegetation-atmosphere interaction can occur on monthly timescales. The groundwater system, which is often ignored in most climate models, does have impacts on precipitation over the Central U.S. DEFAULT has trouble simulating the overall magnitude of precipitation over the Central U.S. Of significant note, the augmented model with the new components is capable of capturing the intraseasonal variability of precipitation.

\subsection{Impact on Surface Fluxes}

[19] To gain insight into the mechanism responsible for precipitation differences among different experiments, we plot the time series of latent heat and sensible heat fluxes over the Central U.S. (Figure 6). Clearly, simulated latent heat flux is lower in DEFALUT than those in DV and DVGW. The opposite is true for sensible heat flux. This is because soil moisture is relatively dry in the absence of feedbacks among vegetation, groundwater and precipitation. We also noticed that the variations in DEFALUT are less pronounced than those in DV and DVGW, owing to the lack of response to land-vegetation interactions. When the effects of vegetation phenology included in the model, the partitioning between the sensible and latent heat fluxes is affected, resulting in a changed Bowen ratio [Mölders and Rühaak, 2002]. The decrease in the Bowen ratio induced by the vegetation dynamics could potentially increase convection. The increase in convection could bring out more precipitation, and then the increased precipitation can further promote the growth of vegetation. Therefore introducing vegetation-precipitation feedback into the model helps to maintain an appropriate amount of ET over the study area, and hence precipitation. As we included groundwater component in $\mathrm{DV}$, the Bowen ratio further decreased. This can be explained that groundwater adds more water to the dry soil, increasing the latent heat flux. Seuffert et al. [2002] also found that their model when incorporated with a sophisticated hydrological model could increase latent heat flux and reduce sensible heat flux correspondingly. Moreover, an analysis of the results indicates that higher latent heat flux in DV and DVGW corresponds to more precipitation, as described above (Figure 4).

[20] Figure 7 plots the differences in monthly average latent heat flux and precipitation between DV and DEFAULT. A relatively large impact of vegetation growth on latent heat flux and precipitation is particularly seen over the Central U.S. For the most part, the plot shows that the increase in precipitation is consistent with the increase in latent heat flux. On average, a $20 \mathrm{~W} \mathrm{~m}^{-2}$ increase in latent heat flux corresponds to a $0.5-1 \mathrm{~mm} \mathrm{~d}^{-1}$ increase in precipitation. As described by Mölders and Rühaak [2002], changes in latent heat flux (or ET) can alter surface moisture distribution and water availability, which can affect vertical mixing, heating, cloud and precipitation. As a result, the modeling system with vegetation-precipitation feedback included to some extent improves precipitation simulation through changing 

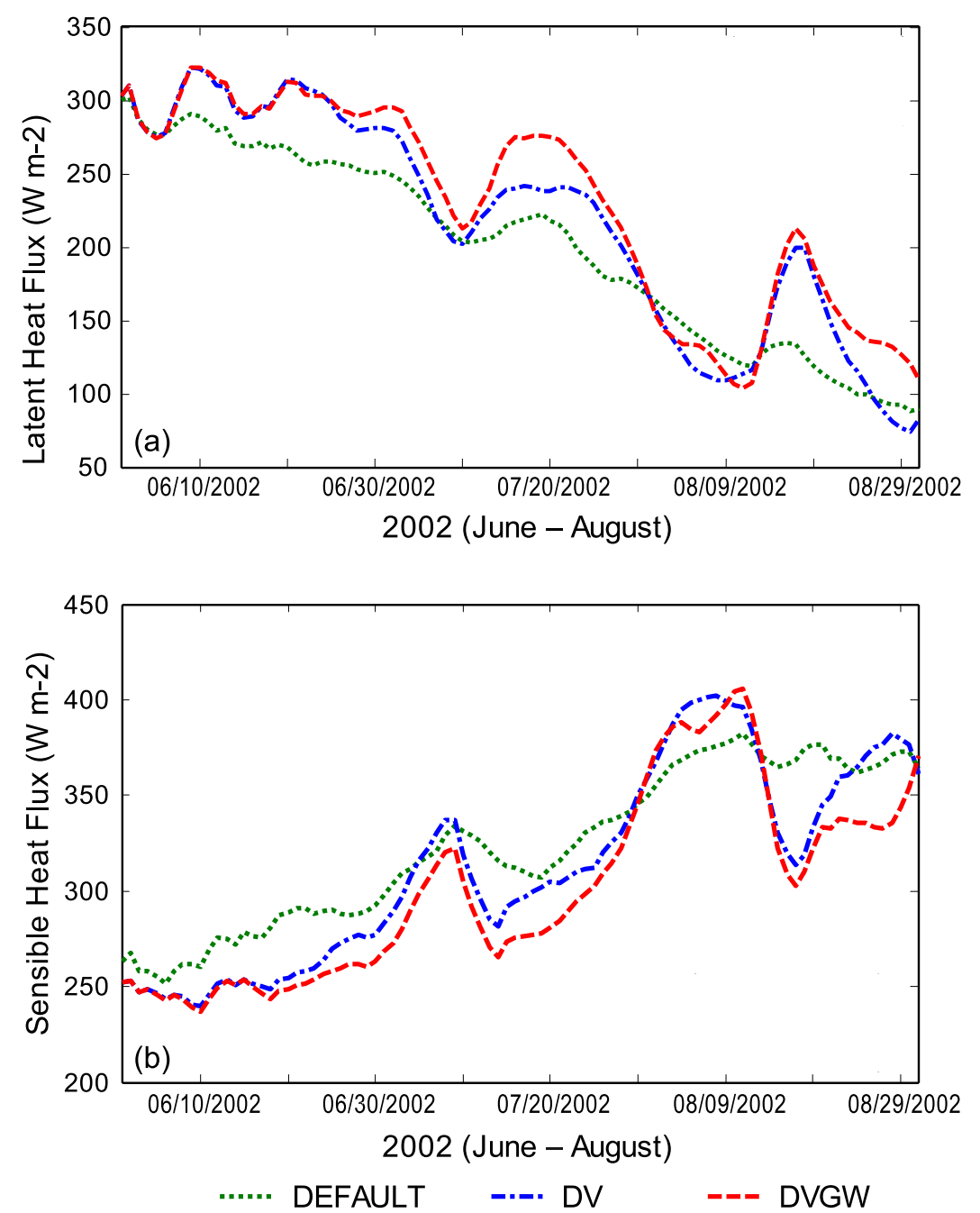

Figure 6. Comparisons of (a) simulated latent heat flux and (b) sensible heat flux over the Central United States among three experiments.

latent heat flux. When we added groundwater component to the second modeling system, again, we see a $30 \mathrm{~W} \mathrm{~m}^{-2}$ increase in latent heat flux between DVGW and DV (Figure 8 ), which corresponds to $1 \mathrm{~mm} \mathrm{~d}^{-1}$ increase in precipitation over this area. The effects of vegetation and groundwater are most pronounced in July and August over the Central U.S., and the impacts of the two new components become more discernible after one month.

[21] In addition to directly examining the evolution and distribution of latent heat flux and sensible heat flux, moisture budget calculation is another way to examine the causes of the increase in precipitation over the Central U.S. We calculated moisture flux convergence over the Central U.S. using specific humidity and wind fields on the basis of the following equations:

$$
\begin{gathered}
Q_{u}=-\frac{1}{g} \int_{P s}^{P t} q u d p, \text { and } \\
Q_{v}=-\frac{1}{g} \int_{P s}^{P t} q v d p,
\end{gathered}
$$

where $Q_{u}$ is the horizontal (east-west) component of moisture flux in $\left[\mathrm{kg} \mathrm{m}^{-1} \mathrm{~s}^{-1}\right], Q_{v}$ is the meridional (northsouth) component of moisture vapor flux in $\left[\mathrm{kg} \mathrm{m}^{-1} \mathrm{~s}^{-1}\right], q$ is the specific humidity $\left[\mathrm{km} \mathrm{km}^{-1}\right], u$ is the horizontal component of wind velocity $\left[\mathrm{m} \mathrm{s}^{-1}\right], v$ is the meridional component of wind velocity $\left[\mathrm{m} \mathrm{s}^{-1}\right], p$ is the pressure $[\mathrm{mb}]$, and $\mathrm{g}$ is the gravitational constant $\left[9.81 \mathrm{~m} \mathrm{~s}^{-2}\right]$. The negative sign arises due to the fact that the hydrostatic assumption is used to convert from elevation to pressure. The limits of integration are the surface pressure $\left(p_{s}\right)$ and the pressure at the "top" of the atmosphere $\left(p_{t}\right)$. Here we define $100 \mathrm{mb}$ as the top of the atmosphere in these computations. The moisture flux convergence is calculated using the following equation:

$$
-\nabla \bullet Q=-\left(\frac{\partial Q_{u}}{\partial x}+\frac{\partial Q_{v}}{\partial y}\right)
$$

The negative sign changes divergence to convergence, which means when the value is negative, it is divergence; and when it is positive, it is convergence. NARR and CPC gauged precipitation data are used as reference data sets. 


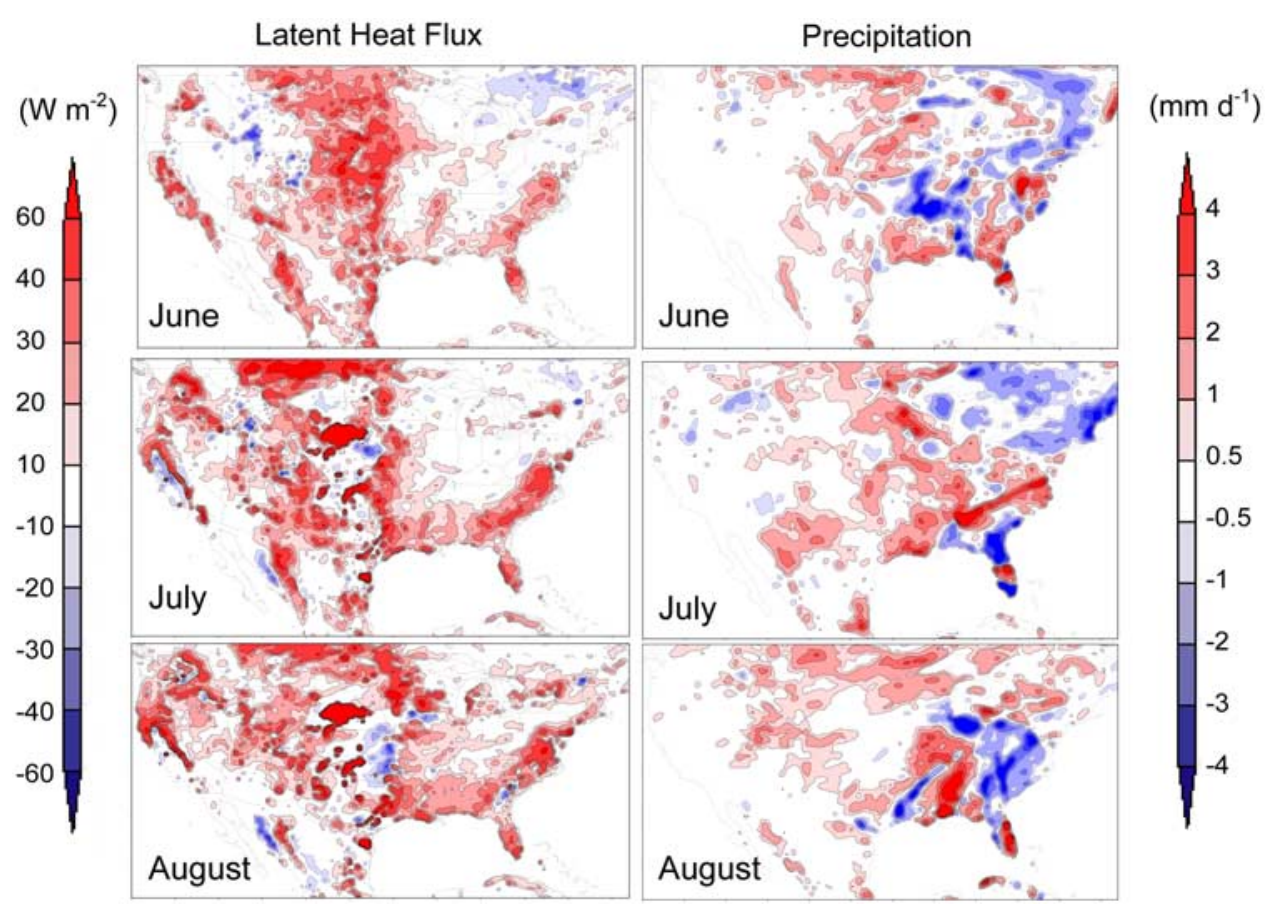

Figure 7. Map of differences in monthly average latent heat flux $\left(\mathrm{W} \mathrm{m}^{-2}\right)$ and precipitation $\left(\mathrm{mm} \mathrm{d}^{-1}\right)$ between DV and DEFAULT experiments. Differences were computed from ensemble simulations of DV and DEFAULT. The domain covers the contiguous U.S. $\left(21^{\circ} \mathrm{N}-50^{\circ} \mathrm{N}, 125^{\circ} \mathrm{W}-68^{\circ} \mathrm{W}\right)$.

[22] Again, the calculated results (Table 2) show that DEFAULT largely underestimates the JJA precipitation by a factor of two. DV increases the JJA precipitation by $0.5 \mathrm{~mm} \mathrm{~d}^{-1}$. The difference between DVGW and the observations is the smallest, with about $0.3 \mathrm{~mm} \mathrm{~d}^{-1}$. The calculated ET shows that the amount of increased precipi- tation comes from increased ET. In summer, ET is larger than precipitation in the Central U.S. The moisture flux convergence is divergence, suggesting moisture flows out of this area. This result is consistent with several previous studies [Ropelewski and Yarosh, 1998; Ruiz-Barradas and Nigam, 2006], in which the authors found that the Central

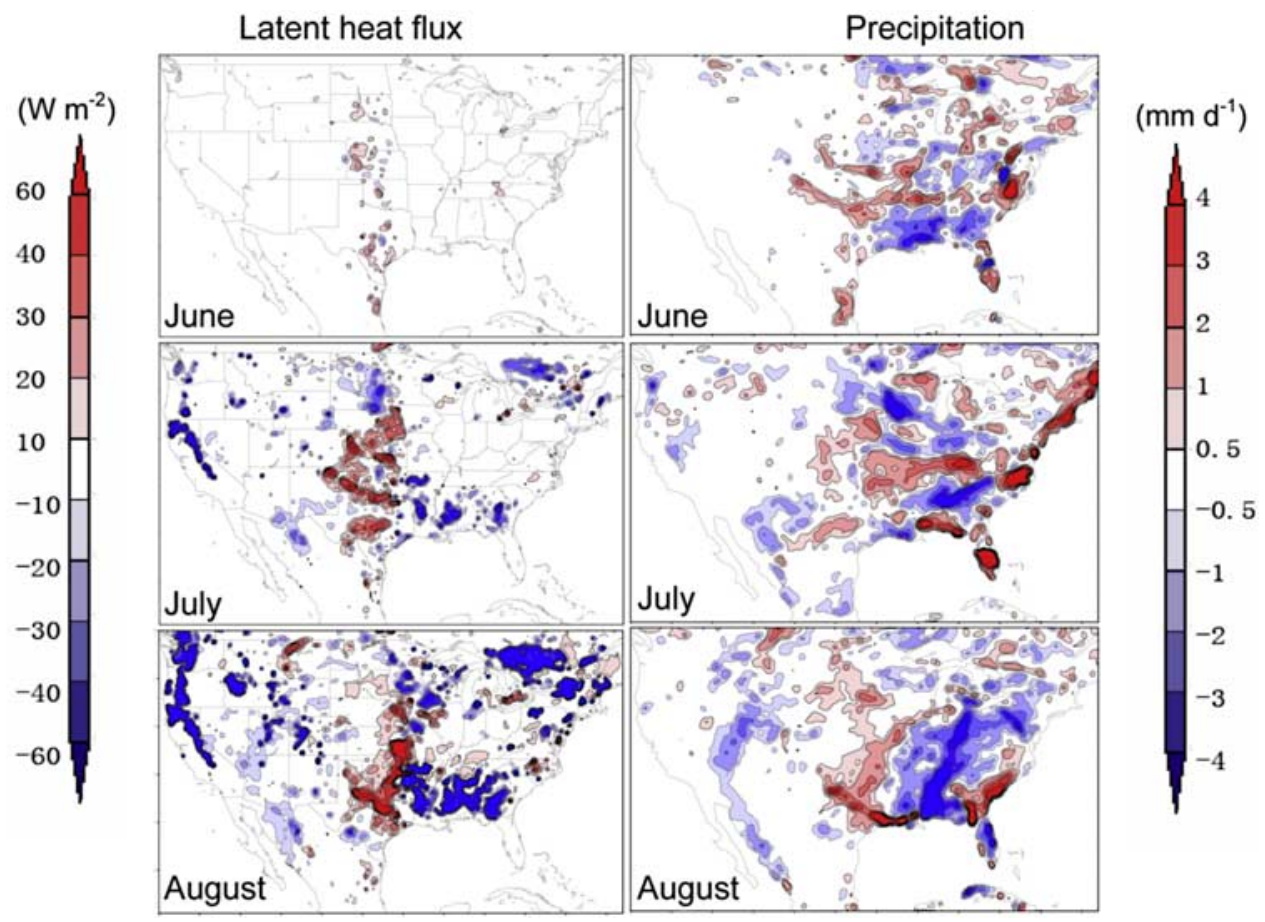

Figure 8. As in Figure 7, but for differences between DVGW and DV. 
Table 2. Water Budget Over the Central United States in June, July, and August 2002

\begin{tabular}{llcc}
\hline Variables & $\begin{array}{c}\text { Precipitation } \\
\left(\mathrm{mm} \mathrm{d}^{-1}\right)\end{array}$ & $\begin{array}{c}\text { Evapotranspiration } \\
\left(\mathrm{mm} \mathrm{d}^{-1}\right)\end{array}$ & $\begin{array}{c}\text { Moisture Flux } \\
\text { Convergence }\left(\mathrm{mm} \mathrm{d}^{-1}\right)\end{array}$ \\
\hline NARR & $2.3642^{\mathrm{a}} / 2.5186$ & 2.9907 & -0.4912 \\
DEFAULT & 1.2575 & 2.3181 & -0.8660 \\
DV & 1.7215 & 2.9624 & -1.0313 \\
DVGW & 2.0825 & 3.1033 & -1.2663 \\
GW & 1.4614 & 2.2931 & -1.4180 \\
\hline
\end{tabular}

${ }^{\mathrm{a}} \mathrm{CPC}$ precipitation data.

U.S. acts as a net moisture source during the summer months and mean evaporation exceeds mean precipitation with largest evaporation in July and August. As we discussed here, in our results, the Central U.S. does act as a net moisture source. The increased precipitation by DVGW is almost $65 \%$, corresponding to $34 \%$ increase in latent heat flux. The summer precipitation in the Central U.S. mostly comes from local ET, showing a strong land-atmosphere coupling in this region. The role of vegetation accounts for almost $37 \%$ increase in precipitation in summer and the contribution of groundwater to summer precipitation is about $16 \%$. We also performed one sensitivity experiment called GW, which only accounts for groundwater effect, to examine the contribution of groundwater dynamics. The result shows that groundwater alone only contributes to $0.2 \mathrm{~mm} \mathrm{~d}^{-1}$ increase in the JJA precipitation. Apparently, when we include vegetation and groundwater together in the model, there is an interaction between them, which can enhance the model performance.

\subsection{Impact on Vegetation Greenness Fraction (VGF)}

[23] Variability of vegetation can modulate surface energy fluxes and alter the partitioning of available energy into sensible and latent heat fluxes via the closing or opening of stomata, VGF, LAI and vegetation types [e.g., Sud et al., 1993; Eastman et al., 2001]. The change of wet or dry season is tightly linked to vegetation variability. One variable often used to represent vegetation variability and condition is
VGF. Thus one way to examine the role that dynamic vegetation and groundwater play is to compare the simulated VGF with observations.

[24] Because the variation of VGF is highly correlated to NDVI, we followed the method defined by Gutman and Ignatov [1998] to derive VGF from the MODIS NDVI data. The MODIS NDVI data we used is a 16-day interval data set downloaded from http://glcf.umiacs.umd.edu/data/ndvi/ [NASA, 2007]. The spatial resolution of this data set is $250 \mathrm{~m}$ and ArcGIS software is used to upscale the data to model spatial resolution. The VGF is calculated according to the following equation [Gutman and Ignatov, 1998]:

$$
V G F=\frac{N D V I_{i}-N D V I_{\min }}{N D V I_{\max }-N D V I_{\min }}
$$

where $N D V I_{\min }=0.04$ and $N D V I_{\max }=0.52$ are prescribed as global constants. The analysis above illustrated the effects of vegetation and groundwater are most pronounced in August, we thus compared simulated August VGF over the Central U.S. with MODIS NDVI-derived data (Figure 9). In August, the prescribed AVHRR-derived VGF over the Central U.S. is lower than MODIS-derived one. Incorporation of vegetation growth and groundwater dynamics in the model increases VGF by $9 \%-11 \%$, resulting in a $0.5-$ $1.0 \mathrm{~mm} \mathrm{~d} \mathrm{~d}^{-1}$ increase in precipitation as indicated in Figure 5. This suggests that the long-term averaged VGF may not well represent actual vegetation conditions in the simulation period. With the vegetation phenology included, the modeling system is capable of maintaining ET through vegetation-precipitation feedback. As mentioned in section 2.2, the year we selected to do these experiments is wetter than normal, corresponding to higher VGF. The default climatological VGF data used in the models do not reflect the vegetation conditions in our simulation period. With the additional consideration of upward recharge from the groundwater, plants tend to grow much better, resulting in higher VGF. Without this effect, during the dry period, plants cannot get enough

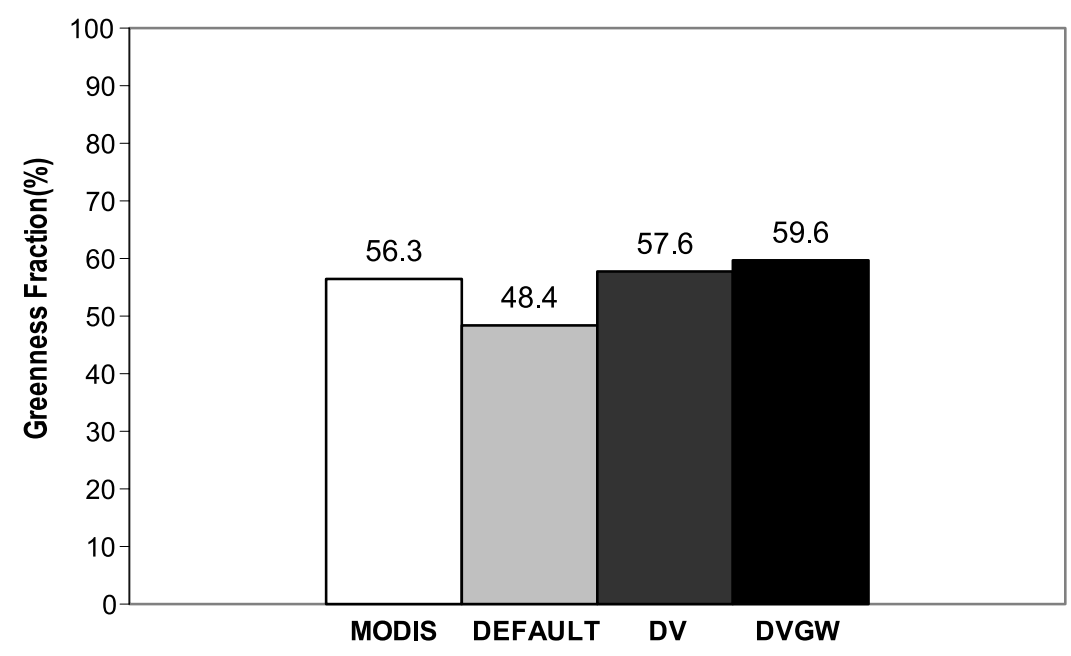

Figure 9. MODIS NDVI-derived and model simulated VGF over the Central United States in August. The MODIS NDVI data we used is a 16-day interval data set downloaded from http:// glcf.umiacs.umd.edu/data/modis/. The VGF is calculated by following the method defined in the work of Gutman and Ignatov [1998]. 

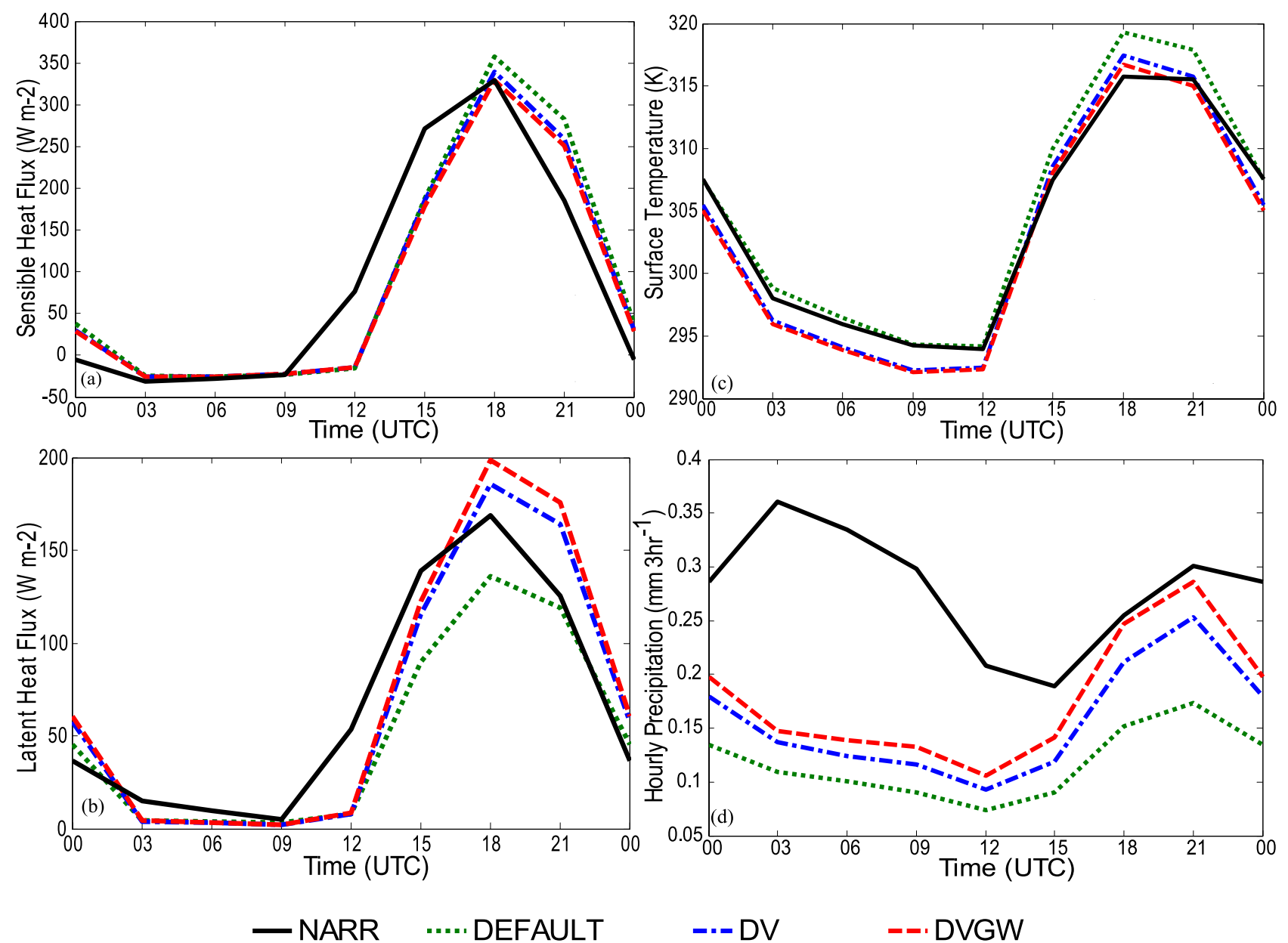

Figure 10. Observed and simulated diurnal cycles of (a) sensible heat flux, (b) latent heat flux, (c) surface temperature, and (d) precipitation over the Central United States. All variables were computed using the 3-month (JJA) data.

water to generate more ET and greenness fraction. It is very intriguing that the impacts of vegetation and groundwater dynamics on VGF are consistent with the impacts on latent heat flux and precipitation. Although, most previous work shows it is very difficult to find the positive correlation between vegetation and precipitation at local scales [Matsui et al., 2005; Liu et al., 2006]. In our results, the impacts of vegetation and groundwater on vegetation condition lie in the region where there is an increase in precipitation.

\subsection{Impact on Diurnal Cycles of Precipitation and Surface Fluxes}

[25] It is of interest to explore the possible effects of vegetation growth and groundwater dynamics on diurnal cycles of precipitation and surface fluxes. A motivation to look at the impacts on diurnal cycles is because most climate and weather models cannot get diurnal cycle of precipitation right due to the uncertainties in the convective parameterizations, cloud physics and other land surface parameterizations, in which the uncertainties in the land surface model have a potential impact on this issue [Dai and Trenberth, 2004].

[26] The diurnal cycles of surface heat fluxes, surface temperature and precipitation simulated by three modeling systems over the Central U.S. are evaluated against the NARR data set. As seen from Figure 10, the effects of vegetation and groundwater on diurnal cycles of surface fluxes are typically from noon to early evening (local time). When compared to the NARR data, DEFALUT overestimates sensible heat flux, but underestimates latent heat flux. When vegetation phenology considered, the model produces somewhat higher latent heat flux and lower sensible heat flux. Changes in the surface fluxes in DV, because of changes in vegetation conditions, further improves the capability of the model to simulate diurnal cycles of surface temperature and precipitation (Figures 10c and 10d). This analysis supports the findings presented by Holt et al. [2006] that including vegetation phenology in a coupled model enhances the coupling between the surface and the overlying atmosphere. As we incorporated groundwater into DV, the modeling system further reduces sensible heat flux and increases latent heat flux. This feature has also been reported in other studies [e.g., Seuffert et al., 2002], where the authors found that the model with the inclusion of groundwater and lateral water transport increases latent heat flux by increasing soil moisture content. It was thus concluded that DVGW makes better estimates of surface heat fluxes, and improves the simulations of surface temperature and precipitation. In addition, the model when 
enhanced with vegetation and groundwater dynamics is capable of simulating the later afternoon rainfall peak, which is not well captured in the default model.

[27] The results presented here imply that when considering variation in vegetation phenology, the capability of the model to simulate the diurnal peak is improved. Moreover, if there is an impact of groundwater included in the model, during the dry period, the upward recharge from groundwater can increase precipitation throughout the whole day and the impacts are most significant from the late afternoon to the early morning. However, the nighttime precipitation peak, which is clearly shown in the NARR data set, cannot be well simulated in all experiments. The reason can be explained that in the early morning, the dominant factor controlling the precipitation is not mainly from the local evaporation, the large-scale moisture transport might play an important role in producing precipitation. Still, our models with these two augments cannot improve the capability of the climate model to simulate synoptic scale systems. Other improvements such as more appropriate cloud microphysics, convective schemes are required in regional climate models to better simulate precipitation.

\subsection{Impact on Coupling Between Soil Moisture and Lifting Condensation Level (LCL)}

[28] Land-atmosphere system is a highly coupled one, and the relationship between LCL and soil moisture index (SMI) is suggestive of important coupling within the system [Betts, 2007]. Some studies [Betts, 2004, 2007; Betts and Viterbo, 2005] have found a strong link between soil moisture and LCL in reanalysis data.

[29] To examine the coupling between the land and atmosphere, we examined the relationship between soil moisture and LCL using the method defined by Betts [1997, 2007]. Estimates of the mean heights of the cloud base and LCL in pressure coordinates were computed from the lowest model level data using the formula below [Betts, 1997]:

$$
P_{L C L} / p=(1-R H) /(A+(A-1) R H),
$$

where $p$ is the pressure at the lowest model level (about $1 \mathrm{hPa}$ from the surface) and the thermodynamic coefficient $A=(0.622 L / 2 C p T)$ is a weak function of Kelvin temperature, $T$, with $L$ being the latent heat of vaporization and $C p$ the specific heat of air at constant pressure. SMI for the first soil layer and all soil layers is defined as:

$$
S M I=(S M-S W P) /(S M C-S W P),
$$

where $S M$ is the model soil water fraction, $S W P$ and $S M C$ are the model soil permanent wilting and the soil porosity, which depend on different types of soil texture [Betts, 2007]. As a result, $S M I$ is not only a useful index on the daily timescale for the availability of water for evaporation, but it also responds to precipitation on the intraseasonal scale. Thus the two-way interaction of soil moistureatmosphere coupling can be representing LCL as a function of SMI.

[30] Figure 11 illustrates the relationship between daily averaged LCL and SMI, in which the NARR data are used as our reference. It is known that soil moisture, especially in the upper layer responses directly to precipitation. The evaporation from the land surface increases relative humidity and lowers the LCL. So lower value of LCL is corresponding to higher soil moisture index. Increased soil moisture due to the two augments is associated with a lower LCL and an increase in precipitation. Consistent with the results of Mölders and Rühaak [2002], Figure 11 shows that when vegetation phenology included in the model, the modeled ET is affected because of redistribution of vegetation conditions or VGF. As a consequence of the altered ET, the surface moisture distribution and water availability differ. This can further alter vertical mixing, and affect cloud and precipitation formation. The changed pattern and amount of precipitation can in turn influence vegetation conditions through affecting soil water content. As seen here, the feedback between vegetation and atmosphere is enhanced when vegetation dynamics is included in the model [Holt et al., 2006]. As we added groundwater to the model in addition to vegetation, the LCL is further lowered for the same level of SMI. Maxwell et al. [2007] investigated the relationship between soil moisture and the boundary layer evolution by adding a coupled groundwater model to an atmospheric model. Their results show a spatial correlation between water table depth and boundary layer height. In general, a shallower water table tends to lead to wetter soil moisture, cooler surface temperature and hence a lower boundary layer height. These features are also consistent with the aforementioned impacts of groundwater on surface fluxes. The impact of groundwater on soil moisture and LCL is more significant when a soil is drier, while the influence is relatively small when a soil becomes highly saturated. By examining the two plots in Figure 11, one can find that the impact of groundwater on the bottom soil layer is more distinctive, suggesting the direct interaction between the bottom soil layer and the groundwater system. Over the region we are interested in, the groundwater tends to increase soil moisture and lower LCL, resulting in an increase in precipitation. Thus by incorporating vegetation and groundwater dynamics in the model, the coupling between soil moisture and precipitation is enhanced. The result agrees well with what we found above that an increase in precipitation over the Central U.S. is due to local ET. The relationship between the LCL and the SMI exhibits an improvement as we incorporated dynamic vegetation and groundwater in the model, which is much closer to the NARR data.

\section{Summary}

[31] This paper described the applications of vegetation and groundwater dynamics in a coupled land-atmosphere model over the Central U.S. Several sensitivity experiments with and without the two augments are designed to examine the impacts of vegetation and groundwater dynamics on warm season forecasts of precipitation. Our results show that the model with the considerations of vegetation growth and groundwater dynamics improves the simulations of summer precipitation over the Central U.S. In this region, the default model produces less precipitation in comparison to observations. When vegetation growth is included in the model, more precipitation is seen, as perhaps induced by vegetation-atmosphere feedback. When we added a ground- 

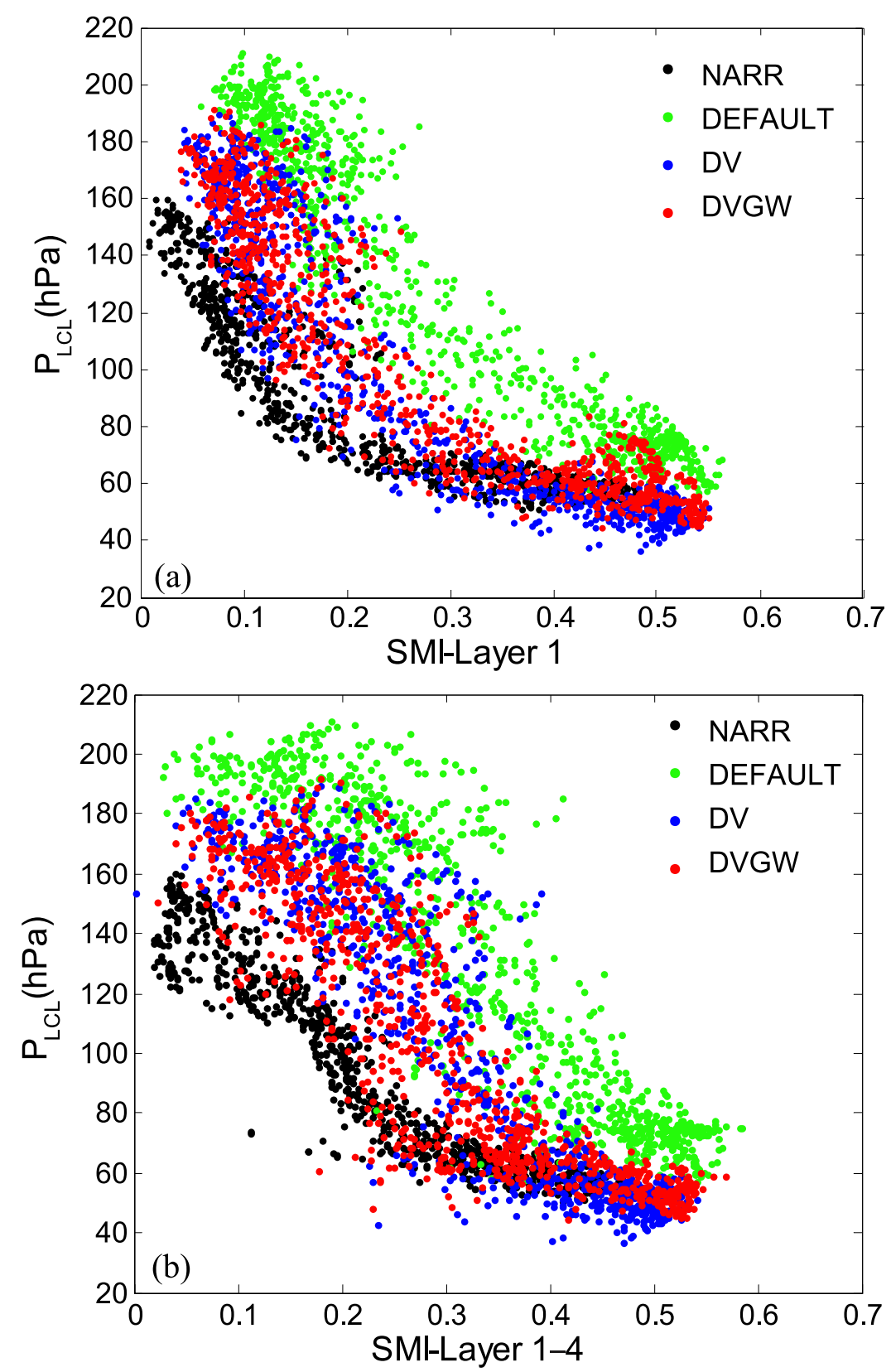

Figure 11. Daily averaged lifting condensation level (LCL) versus soil moisture index (SMI) for (a) soil layer 1 and (b) soil layers 1-4. Estimates of the height of the LCL in pressure coordinates were computed from the lowest model level data using the formula defined by the work of Betts [1997].

water component to the model in addition to vegetation growth, the performance of the model in simulating summer precipitation is further enhanced, which is attributed to the interactions among soil moisture, vegetation and groundwater. These results also suggest that vegetation growth and groundwater dynamics play an important role in enhancing the persistence of seasonal precipitation in the regional climate model. Through the analysis of the relationship between surface fluxes and precipitation, more precipitation generated by DV and DVGW corresponds to higher latent heat flux and lower sensible heat flux.

[32] It is evident from the discussed Figures 1-11 and Tables 1 and 2 that local ET is an important water vapor source for summer precipitation over the Central U.S., suggesting a strong land-atmosphere coupling in this region. Vegetation and groundwater over the Central U.S. act to favor a stronger land-atmosphere feedback during summer season. Detailed analyses of the simulations suggest that the impacts of vegetation and groundwater on both energy and water budgets are critical in determining the strength of the feedback. It is also found that the two components have pronounced impacts on the diurnal cycles of surface fluxes and precipitation. The simulated diurnal cycle of precipitation is improved by the augmented model with the two components. This result may have broad implications for the development of climate models.

[33] Finally, the coupling between soil moisture and lifting condensation level is examined by scatterplots of 
the two variables. The impact of groundwater is significant when the soil moisture is relatively dry. This is not surprising since groundwater systems have a long memory. In addition, it appears that groundwater dynamics has a larger impact on the bottom soil layer. This result emphasizes the possible role groundwater systems play in climate prediction. If land surface models used in climate models lack groundwater systems, the skill of the models might be reduced.

[34] The results presented in this study demonstrate the feasibility of coupling climate models with dynamic representations of vegetation growth and groundwater recharge. However, in this work, we did not include the effects of lateral flow, but only considered the vertical water exchange between soil and its underlying unconfined aquifer. In future studies, a more sophisticated physically based three-dimension groundwater model is needed in the coupled land-atmosphere model to study the feedbacks. This study only discussed the impacts of the two components on one summer season. Additional simulations of different years using these two components in the coupled model are required to gain a better sense of how the timing of the soil moisture affected by vegetation and groundwater influences seasonal precipitation. Continued development of fully coupled climate-vegetation-groundwater models will facilitate the exploration of a broad range of global change issues, including the potential roles of vegetation and groundwater feedbacks within the climate system.

[35] Acknowledgments. This research is supported by NOAA grant NA070AR4310216 and NASA Headquarters under the NASA Earth and Space Science Fellowship Program grant NNX07AO28H. We would like to express our thanks to David Gochis, Kenneth Mitchell, Lindsey Gulden, Enrique Rosero, and the anonymous reviewers for their insightful and constructive comments. The computing resources are provided by Texas Advanced Computing Center (TACC).

\section{References}

Anyah, R. O., C. P. Weaver, G. Miguez-Macho, Y. Fan, and A. Robock (2008), Incorporating water table dynamics in climate modeling: 3. Simulated groundwater influence on coupled land-atmosphere variability, J. Geophys. Res., 113, D07103, doi:10.1029/2007JD009087.

Beljaars, A. C. M., P. Viterbo, M. J. Miller, and A. K. Betts (1996), The anomalous rainfall over the United States during July 1993 - Sensitivity to land-surface parameterization and soil moisture, Mon. Weather Rev., $124,362-383$.

Betts, A. K. (1997), The parameterization of deep convection, in The Physics and Parameterization of Moist Atmospheric Convection, edited by R. K. Smith, chap. 10, NATO ASI Ser. C, 505, 255-279.

Betts, A. K. (2004), Understanding hydrometeorology using global models, Bull. Am. Meteorol. Soc., 85, 1673-1688.

Betts, A. K. (2007), Coupling of water vapor convergence, clouds, precipitation, and land-surface processes, J. Geophys. Res., 112, D10108, doi:10.1029/2006JD008191.

Betts, A. K., and P. Viterbo (2005), Land-surface, boundary layer and cloud-field coupling over the south-western Amazon in ERA-40, J. Geophys. Res., 110, D14108, doi:10.1029/2004JD005702.

Beven, K. J., and M. J. Kirkby (1979), A physically based, variable contributing model of basin hydrology, Hydrol. Sci. Bull., 24, 43-69.

Bierkens, M. F. P., and B. J. J. M. van den Hurk (2007), Groundwater convergence as a possible mechanism for multi-year persistence in rainfall, Geophys. Res. Lett., 34, L02402, doi:10.1029/2006GL028396.

Chen, F., and J. Dudhia (2001), Coupling an advanced land surfacehydrology model with the Penn State-NCAR MM5 modeling system. Part 1: Model implementation and sensitivity, Mon. Weather Rev., $129,569-585$.

Chase, T. N., R. A. Pielke, T. G. F. Kittel, R. Nemani, and S. W. Running (1996), Sensitivity of a general circulation model to global changes in leaf area index, J. Geophys. Res., 101(D3), 7393-7408.

Chase, T. N., R. A. Pielke, T. G. F. Kittel, R. R. Nemani, and S. W. Running (2000), Simulated impacts of historical land cover changes on global climate in northern winter, Clim. Dyn., 16, 93-105.
Collatz, G. J., J. T. Ball, C. Grivet, and J. A. Berry (1991), Physiological and environmental regulation of stomatal conductance, photosynthesis and transpiration-a model that includes a laminar boundary layer, Agric. For. Meteorol., 54(2-4), 107-136.

Dai, A., and K. Trenberth (2004), The diurnal cycle and its depiction in the community climate system model, J. Clim., 17, 930-951.

Dekker, S. C., M. Pietkerk, and M. F. P. Bierkens (2007), Coupling microscale vegetation-soil water and macroscale vegetation-precipitation feedbacks in semiarid ecosystems, Global Change Biol., 13(3), 671-678.

Dickinson, R. E., M. Shaikh, R. Bryant, and L. Graumlich (1998), Interactive canopies for a climate model, J. Clim., 11, 2823-2836.

Dirmeyer, P. A. (2006), The hydrologic feedback pathway for land-climate coupling, J. Hydrometeorol., 7, 857-867.

Dong, J., W. Ni-Meister, and P. R. Houser (2007), Impacts of vegetation and cold season processes on soil moisture and climate relationships over Eurasia, J. Geophys. Res., 112, D09106, doi:10.1029/2006JD007774.

Dudhia, J. (1989), Numerical study of convection observed during the winter monsoon experiment using a mesoscale two-dimensional model, J. Atmos. Sci., 46, 3077-3107.

Eastman, J. L., M. B. Coughenour, and R. A. Pielke Sr. (2001), The effects of $\mathrm{CO}_{2}$ and landscape change using a coupled plant and meteorological model, Global Change Biol., 7, 797-815.

Famiglietti, J. S., and E. F. Wood (1994), Multiscale modeling of spatially variable water and energy balance processes, Water Resour. Res., 30(11), 3061-3078.

Fan, Y., G. Miguez-Macho, C. P. Weaver, R. Walko, and A. Robock (2007), Incorporating water table dynamics in climate modeling: 1. Water table observations and the equilibrium water table, J. Geophys. Res., 112, D10125, doi:10.1029/2006JD008111.

Gallo, K., L. Ji, B. Reed, J. Dwyer, and J. Eidenshink (2004), Comparison of MODIS and AVHRR 16-day normalized difference vegetation index composite data, Geophys. Res. Lett., 31, L07502, doi:10.1029/ 2003GL019385.

Guo, Z., et al. (2006), GLACE: The global land-atmosphere coupling experiment. Part II: Analysis, J. Hydrometeorol., 7(4), 611-625.

Gutman, G., and A. Ignatov (1998), Derivation of green vegetation fraction from NOAA/AVHRR for use in numerical weather prediction models, Int. J. Remote Sens., 19, 1533-1543.

Gutowski, W. J., Jr., C. J. Vörösmarty, M. Person, Z. Ötles, B. Fekete, and J. York (2002), A coupled land-atmosphere simulation program (CLASP): Calibration and validation, J. Geophys. Res., 107(D16), 4283, doi:10.1029/2001JD000392.

Higgins, R. W., W. Shi, and E. Yarosh (2000), Improved United States precipitation quality control system and analysis, NCEP/Climate Prediction Center Atlas No. 7, 40 pp., U.S. Dep. of Commer., NOAA, NWS. (Available at http://www.cpc.ncep.noaa.gov/research_papers/ncep_cpc_ atlas/7/index.html)

Hoffmann, W. A., and R. B. Jackson (2000), Vegetation-climate feedbacks in the conversion of tropical savanna to grassland, J. Clim., 13, 1593-1602.

Holt, T. R., D. Niyogi, F. Chen, K. Manning, M. A. LeMone, and A. Qureshi (2006), Effect of Land-Atmosphere Interactions on the IHOP 24-25 May 2002 Convection Case, Mon. Weather Rev., 134, 113-133.

Hong, S. Y., and H. L. Pan (1996), Nonlocal boundary layer vertical diffusion in a medium-range forecast model, Mon. Weather Rev., 124, 2322 2339.

Kain, J. S., and M. Fritsch (1990), A one-dimensional entraining/detraining plume model and its application in convective parameterization, J. Atmos. Sci., 47, 2784-2802.

Kim, Y. J., and G. L. Wang (2007), Impact of vegetation feedback on the response of precipitation to antecedent soil moisture anomalies over North America, J. Hydrometeorol., 8(3), 534-550.

Kollet, S. J., and R. M. Maxwell (2008), Capturing the influence of groundwater dynamics on land surface processes using an integrated, distributed watershed model, Water Resour. Res., 44, W02402, doi:10.1029/ 2007WR006004.

Koster, R., and M. J. Suarez (2000), Soil moisture memory in climate models, J. Hydrometeorol., 2, 558-570.

Koster, R. D., et al. (2004), Regions of strong coupling between soil moisture and precipitation, Science, 305, 1138-1140.

Liang, X., Z. Xie, and M. Huang (2003), A new parameterization for surface and groundwater interactions and its impact on water budgets with the variable infiltration capacity (VIC) land surface model, J. Geophys. Res., 108(D16), 8613, doi:10.1029/2002JD003090.

Lin, Y.-L., R. D. Rarley, and H. D. Orville (1983), Bulk parameterization of the snow field in a cloud model, J. Appl. Meteorol., 22, 1065-1092.

Liu, Z., M. Notaro, J. Kutzbach, and N. Liu (2006), Assessing global vegetation-climate feedbacks from observations, J. Clim., 19(5), 787814.

Lo, J. C.-F., Z.-L. Yang, and R. A. Pielke Sr. (2008), Assessment of three dynamical climate downscaling methods using the Weather Research and 
Forecasting (WRF) model, J. Geophys. Res., 113, D09112, doi:10.1029/ 2007JD009216.

Lorenz, E. N. (1963), The predictability of hydrodynamic flow, Trans. N. Y. Acad. Sci., 25B, 409-432.

Lorenz, E. N. (1969), The predictability of a flow which possesses many scales of motion, Tellus, 21, 289-307.

Matsui, T., V. Lakshmi, and E. E. Small (2005), The effects of satellitederived vegetation cover variability on simulated land-atmosphere interactions in the NAMS, J. Clim., 18(1), 21-40.

Maxwell, R. M., and S. J. Kollet (2008), Interdependence of groundwater dynamics and land-energy feedbacks under climate change, Nat. Geosci., $1,665-669$.

Maxwell, R. M., and N. L. Miller (2005), Development of a coupled land surface and groundwater model, J. Hydrometeorol., 6, 233-247.

Maxwell, R. M., F. K. Chow, and S. J. Kollet (2007), The groundwaterland-surface-atmosphere connection: Soil moisture effects on the atmospheric boundary layer in fully-coupled simulations, Adv. Wat. Resour., 30, 2447-2466.

Mesinger, F., et al. (2006), North American regional reanalysis, Bull. Am. Meteorol. Soc., 87, 343-360.

Mlawer, E. J., S. J. Taubman, P. D. Brown, M. J. Iacono, and S. A. Clough (1997), Radiative transfer for inhomogeneous atmospheres: RRTM, a validated correlated-k model for the longwave, J. Geophys. Res. 102(D14), 16,663-16,682.

Mölders, N., and W. Rühaak (2002), On the impact of explicitly predicted runoff on the simulated atmospheric response to small-scale land-use changes-an integrated modeling approach, Atmos. Res., 63, 3-38.

NASA (2007), MODIS 16-day Composite MOD44C, Collection 4, Global Land Cover Facility, Univ. of Maryland, College Park, Md.

Notaro, M., S. Vavrus, and Z. Liu (2007), Global vegetation and climate change due to future increases in $\mathrm{CO}_{2}$ as projected by a fully coupled model with dynamic vegetation, J. Clim., 20(1), 70-90.

Niu, G.-Y., Z.-L. Yang, R. E. Dickinson, and L. E. Gulden (2005), A simple TOPMODEL-based runoff parameterization (SIMTOP) for use in global climate models, J. Geophys. Res., 110, D21106, doi:10.1029/ 2005JD006111.

Niu, G.-Y., Z.-L. Yang, R. E. Dickinson, L. E. Gulden, and H. Su (2007), Development of a simple groundwater model for use in climate models and evaluation with gravity recovery and climate experiment data, J. Geophys. Res., 112, D07103, doi:10.1029/2006JD007522.

Pielke, R. A., Sr., G. E. Liston, J. L. Eastman, L. Lu, and M. Coughenour (1999), Seasonal weather prediction as an initial value problem, J. Geophys. Res., 104(D16), 19,463-19,480.

Ropelewski, C. F., and E. S. Yarosh (1998), The observed mean annual cycle of moisture budgets over the central United States (1973-92), J. Clim., 11, 2180-2190.

Ruiz-Barradas, A., and S. Nigam (2006), Great Plains hydroclimate variability: The view from North American Regional Reanalysis, J. Clim., 19, $3004-3010$
Seuffert, G., P. Gross, and C. Simmer (2002), The influence of hydrologic modeling on the predicted local weather: Two-way coupling of a mesoscale weather prediction model and a land surface hydrologic model, J. Hydrometeorol., 3, 505-523.

Skamarock, W. C., J. B. Klemp, J. Dudhia, D. O. Gill, D. M. Barker, W. Wang, and J. D. and Powers (2005), A description of the Advanced Research WRF version 2, Tech. Note, NCAR/TN-306+STR, 88 pp., Natl. Cent. for Atmos. Res., Boulder, Colo.

Sud, Y. C., W. C. Chao, and G. K. Walker (1993), Dependence of rainfall on vegetation: Theoretical considerations, simulation experiments, observations, and inferences from simulated atmospheric soundings, J. Arid Environ., 25, 5-18.

Wallace, J. M., E. M. Rasmusson, T. P. Mitchell, V. E. Kousky, E. S Sarachik, and H. von Storch (1998), On the structure and evolution of ENSO-related climate variability in the tropical Pacific: Lessons from TOGA, J. Geophys. Res., 103(C7), 14,241-14,259.

Wang, W., B. T. Anderson, N. Phillips, R. K. Kaufmann, C. Potter, and R. B. Myneni (2006a), Feedbacks of vegetation on summertime climate variability over the North American grasslands. Part I: Statistical analysis, Earth Interact., 10, 1-27.

Wang, W., B. T. Anderson, D. Entekhabi, D. Huang, R. K. Kaufmann, C. Potter, and R. B. Myneni (2006b), Feedbacks of vegetation on summertime climate variability over the North American grasslands. Part II: A coupled stochastic model, Earth Interact., 10, 1-30.

Xue, Y., F. De Sales, W. Li, C. R. Mechoso, C. Nobre, and M. H. H.-Juang (2006), Role of land surface processes in South American monsoon development, J. Clim., 19, 741-762.

Yang, Z.-L., and G.-Y. Niu (2003), The Versatile Integrator of Surface and Atmosphere Processes (VISA). Part 1: Model description, Global Planet. Change, 38, 175-189.

Yang, Z.-L., R. E. Dickinson, A. Henderson-Sellers, and A. J. Pitman (1995), Preliminary study of spin-up processes in land surface models with the first stage data of project for intercomparison of land surface parameterization schemes phase 1(a), J. Geophys. Res., 100(D8), $16,553-16,578$.

Yeh, P.J.-F., and E. A. B. Eltahir (2005), Representation of water table dynamics in a land-surface scheme. Part I: Model development, J. Clim., $18,1861-1880$.

York, J. P., et al. (2002), Putting aquifers into atmospheric simulation models: An example from the Mill Creek Watershed, northeastern Kansas, Adv. Water Resour., 25(2), 221-238.

Yuan, X., Z. Xie, J. Zheng, X. Tian, and Z. Yang (2008), Effects of water table dynamics on regional climate: A case study over east Asian monsoon area, J. Geophys. Res., 113, D21112, doi:10.1029/2008JD010180.

X. Jiang, G.-Y. Niu, and Z.-L. Yang, Department of Geological Sciences, John A. and Katherine G. Jackson School of Geosciences, University of Texas, 1 University Station C1100, Austin, TX 78712-0254, USA. (liang@mail.utexas.edu) 